\title{
Manejo do azevém no estabelecimento inicial de plantas, na ciclagem de nutrientes e no rendimento de grãos do arroz irrigado
}

\author{
Ryegrass management on the initial establishment of plants, \\ nutrient cycling and grain yield of irrigated rice
}

\section{Rafael Bruck Ferreira ${ }^{I}$ Enio Marchesan ${ }^{I I}$ Lucas Lopes Coelho ${ }^{\mathrm{I}}$ Maurício Limberger de Oliveira ${ }^{\mathrm{I}}$ Gustavo Mack Teló ${ }^{I I}$ Alberto Cargnelutti Filho ${ }^{I}$ Gerson Meneghetti Sarzi Sartori ${ }^{I}$}

\section{RESUMO}

\begin{abstract}
O objetivo deste trabalho foi avaliar o efeito de diferentes manejos da cultura do azevém na entressafra do arroz irrigado, sobre o estabelecimento inicial de plantas, a ciclagem de nutrientes e o rendimento de grãos de arroz. O experimento foi conduzido em área de várzea sistematizada durante os anos agrícolas de 2010/11 e 2011/12, sob delineamento de blocos ao acaso, com cinco repetições com os tratamentos constituidos por: épocas de dessecação do azevém, antecedendo a semeadura do arroz, pousio e retirada da palha através da produção de feno de azevém. Há redução do estande inicial de plantas de arroz irrigado à medida que a dessecação do azevém se aproxima da semeadura do arroz. A utilização do azevém em áreas de várzea intensifica a ciclagem de nutrientes, mas recomenda-se que, em azevém não pastejado, a dessecação seja realizada com antecedência de 60 dias antes da semeadura do arroz irrigado para não prejudicar o rendimento de grãos do mesmo. A produção de feno de azevém é uma alternativa viável para a entressafra em áreas de várzea, pois não prejudica o estabelecimento inicial de plantas de arroz irrigado.
\end{abstract}

Palavras-chave: Oryza sativa, sucessão de culturas, cobertura do solo, produção de feno.

\section{ABSTRACT}

The objective of this research was to evaluate the effect of different managements of ryegrass straw in the off-season of irrigated rice on the initial establishment of plants, nutrient cycling and grain yield of the irrigated rice. The experiment was conducted in lowland area during the 2010/11 and 2011/12 crop seasons, in a randomized complete block, with five replications and the treatments were constituted by: ryegrass desiccation timings before the rice planting, fallow and straw removal through ryegrass hay production. There is a reduction of rice stand as there is a delay in the ryegrass desiccation approaches to rice planting.
Use of ryegrass in lowlands intensifies the nutrient cycling; however, it is recommended that in non grazed ryegrass the desiccation should be performed 60 days before the irrigated rice planting without reducing grain yield. Ryegrass hay production is a viable alternative for the off-season in lowlands because it does not reduce the initial establishment of irrigated rice plant.

Key words: Oryza sativa, crops succession, cover crop, hay production.

\section{INTRODUÇÃO}

O sistema de semeadura direta em áreas de várzea pode ser incrementado através da implantação de plantas de cobertura de solo após a colheita do arroz irrigado (Oryza sativa). Essa prática pode incrementar a renda do produtor rural, através da utilização de uma cultura forrageira para produção de feno ou para pastejo. Além disso, esse sistema pode impactar positivamente na sustentabilidade do sistema de produção, em razão da ciclagem de nutrientes oriundos da palha remanescente do arroz irrigado pela cultura sucessora, o que possibilitaria otimizar o uso desses nutrientes e minimizar as suas perdas para o ambiente.

Desse modo, quando se utilizam culturas em sucessão, busca-se, além da ciclagem de nutrientes, o sincronismo entre a liberação destes pela planta de cobertura e a absorção pela cultura sucessora. Nesse sentido, considera-se uma condição ideal

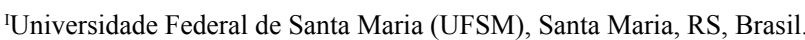

${ }^{I I D}$ partamento de Fitotecnia, Centro de Ciências Rurais (CCR), UFSM, 97105-900, Santa Maria, RS, Brasil. E-mail: eniomarchesan@gmail.com. Autor para correspondência.

IIIEmbrapa Clima Temperado/ CAPES, Estação Experimental de Terras Baixas, Pelotas, RS, Brasil. Recebido 03.11.13 Aprovado 26.03.15 Devolvido pelo autor 04.08.15 CR-2013-1473.R3 
aquela em que o solo esteja sempre coberto por uma espécie de planta em desenvolvimento, dessa forma, determinando alto fluxo de carbono e de energia no sistema solo-planta-atmosfera, beneficiando seus atributos físicos, químicos e biológicos (VEZZANI \& MIELNICZUK, 2009).

O azevém (Lolium multiflorum Lam.) é uma espécie que, além de ser adaptada aos solos de várzea, apresenta baixo custo de sementes, parcial recuperação do nitrogênio residual, rápido estabelecimento, tolerância ao frio, tolerância a doenças, além de auxiliar na supressão de plantas daninhas (REDDY, 2001) ), embora esteja se observando aumento da incidência de brusone em panículas e folhas no azevém, indicando necessidade de pesquisa nesta área para manejo sustentável da sucessão azevém/arroz. No entanto, uma das dificuldades na utilização de plantas de cobertura no período de entressafra é definir o manejo a ser adotado, pois MENEZES et al. (2001) evidenciaram uma diminuição no rendimento de grãos do arroz irrigado, cultivado em sistema de semeadura direta com cobertura de azevém, na entressafra, quando comparado ao sistema convencional de preparo do solo.

Nesse sentido, busca-se melhor entendimento sobre o sistema de semeadura direta em áreas de várzea a fim de se identificar o manejo mais eficiente da planta de cobertura utilizada após a colheita do arroz irrigado. Desse modo, o objetivo deste trabalho foi avaliar o efeito de diferentes manejos na cultura do azevém sobre o estabelecimento inicial de plantas de arroz, a ciclagem de nutrientes e o rendimento de grãos do arroz irrigado.

\section{MATERIAL E MÉTODOS}

O experimento foi conduzido durante os anos agrícolas de 2010/11 e 2011/12, na área didático experimental de várzea do Departamento de Fitotecnia da Universidade Federal de Santa Maria, em Planossolo Hidromórfico Eutrófico arênico, pertencente à unidade de mapeamento Vacacaí (EMBRAPA, 2006).

$\mathrm{O}$ delineamento experimental utilizado foi de blocos ao caso, nas mesmas unidades experimentais para os dois anos agrícolas em estudo, com cinco repetições, e área útil por unidade experimental de $7,65 \mathrm{~m}^{2}(5 \times 1,53 \mathrm{~m})$, composto pelos seguintes tratamentos: [1] feno de azevém I, com corte no florescimento; [2] dessecação do azevém aos 60 dias antes da semeadura do arroz (DAS); [3] dessecação do azevém aos 45 DAS; [4] dessecação do azevém aos 30 DAS; [5] dessecação do azevém aos 30 DAS + rolo-faca (RF); [6] dessecação do azevém 15 DAS + $\mathrm{RF}$; [7] feno de azevém II, com corte no enchimento de grãos; [8] pousio da área antecedendo a semeadura do arroz (área sem azevém).

$O$ azevém foi semeado a lanço nos dois anos de experimento na densidade de $40 \mathrm{~kg}$ ha $^{-1}(27 / 03 / 10$ e 24/03/11). Antes da semeadura, os restos culturais do arroz foram roçados para proporcionar maior contato da palha com o solo e, com isso, favorecer sua decomposição. A adubação nitrogenada no azevém foi parcelada igualmente em três aplicações, aos 20, 45 e 60 dias após a emergência, totalizando $75 \mathrm{~kg} \mathrm{~N} \mathrm{ha}^{-1}$.

Para as dessecações do azevém, foi utilizado o herbicida glyphosate na dose de $960 \mathrm{~g}$ i.a. $\mathrm{ha}^{-1}$, aplicado com pulverizador costal pressurizado por $\mathrm{CO}_{2}$ com volume de calda de $140 \mathrm{~L} \mathrm{ha}^{-1}$, para todos tratamentos. No momento da dessecação, para o tratamento aos 60 DAS, as plantas de azévem encontravam-se com quatro perfilhos, para o tratamento aos 45 DAS em pré-florescimento, aos 30 DAS no florescimento pleno e aos 15 DAS no enchimento de grãos. Nos tratamentos com utilização de rolo-faca, este foi operacionalizado sete dias após a dessecação. Nos tratamentos onde foi realizado feno, as plantas de azevém foram cortadas com auxílio de roçadeira motorizada, a uma altura média de $5 \mathrm{~cm}$ do solo.

A semeadura do arroz ocorreu em 19 e 20 de outubro, respectivamente, para os anos agrícolas de 2010/11 e 2011/12, sendo utilizada a cultivar IRGA 424, na quantidade de $90 \mathrm{~kg}$ de sementes ha-1. A adubação de base foi distribuída na linha de semeadura, sendo utilizado $15 \mathrm{~kg} \mathrm{~N} \mathrm{ha}^{-1}, 60 \mathrm{~kg} \mathrm{P}_{2} \mathrm{O}_{5}$ ha $^{-1}$ e $90 \mathrm{~kg}$ $\mathrm{K}_{2} \mathrm{O}$ ha $^{-1}$. A adubação de cobertura foi dividida em dois momentos, sendo a primeira aplicação realizada com $90 \mathrm{~kg} \mathrm{~N} \mathrm{ha-1} \mathrm{no} \mathrm{estádio} \mathrm{V}_{3}$, conforme escala fenológica proposta por COUNCE et al. (2000), e a segunda aplicação com $45 \mathrm{~kg} \mathrm{~N} \mathrm{ha}^{-1}$ e $30 \mathrm{~kg} \mathrm{~K}_{2} \mathrm{O} \mathrm{ha}^{-1}$ no estádio $\mathrm{R}_{0}$. Os demais tratos culturais foram realizados conforme as recomendações técnicas para a cultura do arroz irrigado no Sul do Brasil (SOSBAI, 2010).

A determinação da quantidade de massa seca remanescente do azevém, no momento da semeadura do arroz irrigado, foi realizada através da coleta de duas amostras de $0,25 \mathrm{~m}^{2}$ por unidade experimental. Após, o material foi mantido em estufa com circulação de ar forçada à temperatura de $65^{\circ} \mathrm{C}$ até atingir peso constante, sendo posteriormente realizada a pesagem.

As avaliações realizadas na cultura do arroz irrigado foram: o estande inicial de plantas realizado aos 10 dias após a emergência, em local representativo da unidade experimental, onde foi demarcado um metro na segunda linha de semeadura 
e efetuada a contagem das plantas; no mesmo local, realizou-se a contagem do número de colmos por planta nos estádios fenológico $\mathrm{V}_{4}, \mathrm{~V}_{5}, \mathrm{~V}_{7}$ e $\mathrm{V}_{9}$, para estimar a evolução e a duração do perfilhamento. Foi avaliado o acúmulo de massa seca nos estádios fenológicos $\mathrm{V}_{3}$ e $\mathrm{V}_{6}$, através da coleta de 20 plantas por unidade experimental, sendo posteriormente levadas à estufa a $65^{\circ} \mathrm{C}$ até atingir peso constante. O rendimento de grãos de arroz foi estimado através da colheita manual em uma área útil de $5,10 \mathrm{~m}^{2}$ $(5 \times 1,02 \mathrm{~m})$, quando os grãos apresentavam grau de umidade média de $22 \%$. Após, realizaram-se os procedimentos de trilha, limpeza, secagem e pesagem dos grãos com casca, sendo os dados corrigidos para $13 \%$ de umidade e convertidos em $\mathrm{kg} \mathrm{ha}^{-1}$.

As análises químicas para determinação dos teores de nitrogênio $(\mathrm{N})$, fósforo $(\mathrm{P})$ e potássio (K) na massa seca do arroz foram realizadas conforme a metodologia descrita por TEDESCO et al. (1995).

Os dados obtidos foram submetidos ao teste das pressuposições do modelo matemático (normalidade e homogeneidade das variáveis). A análise de variância foi realizada através do teste $\mathrm{F}$ e as médias comparadas pelo teste Scott-Knott, ao nível de probabilidade de erro de 5\%. Para os resultados plotados no gráfico, determinou-se o intervalo de confiança $(\mathrm{P} \leq 0,05)$.

\section{RESULTADOS E DISCUSSÃO}

Houve diferença em relação à massa seca remanescente da parte aérea do azevém (Figura 1), com menor quantidade nos manejos de produção de feno e no tratamento com dessecação aos 60 DAS. Esses resultados são esperados, visto que a produção do feno consiste no corte do azevém e na retirada deste da área. Da mesma forma, a dessecação realizada aos 60 DAS proporciona maior tempo para a decomposição dos resíduos vegetais pelos microrganismos do solo (CRUSCIOL et al., 2008), evidenciando assim menor quantidade de massa seca remanescente. Com o atraso da época de dessecação, ocorreu o aumento da massa seca remanescente do azevém na superfície do solo, sendo importante

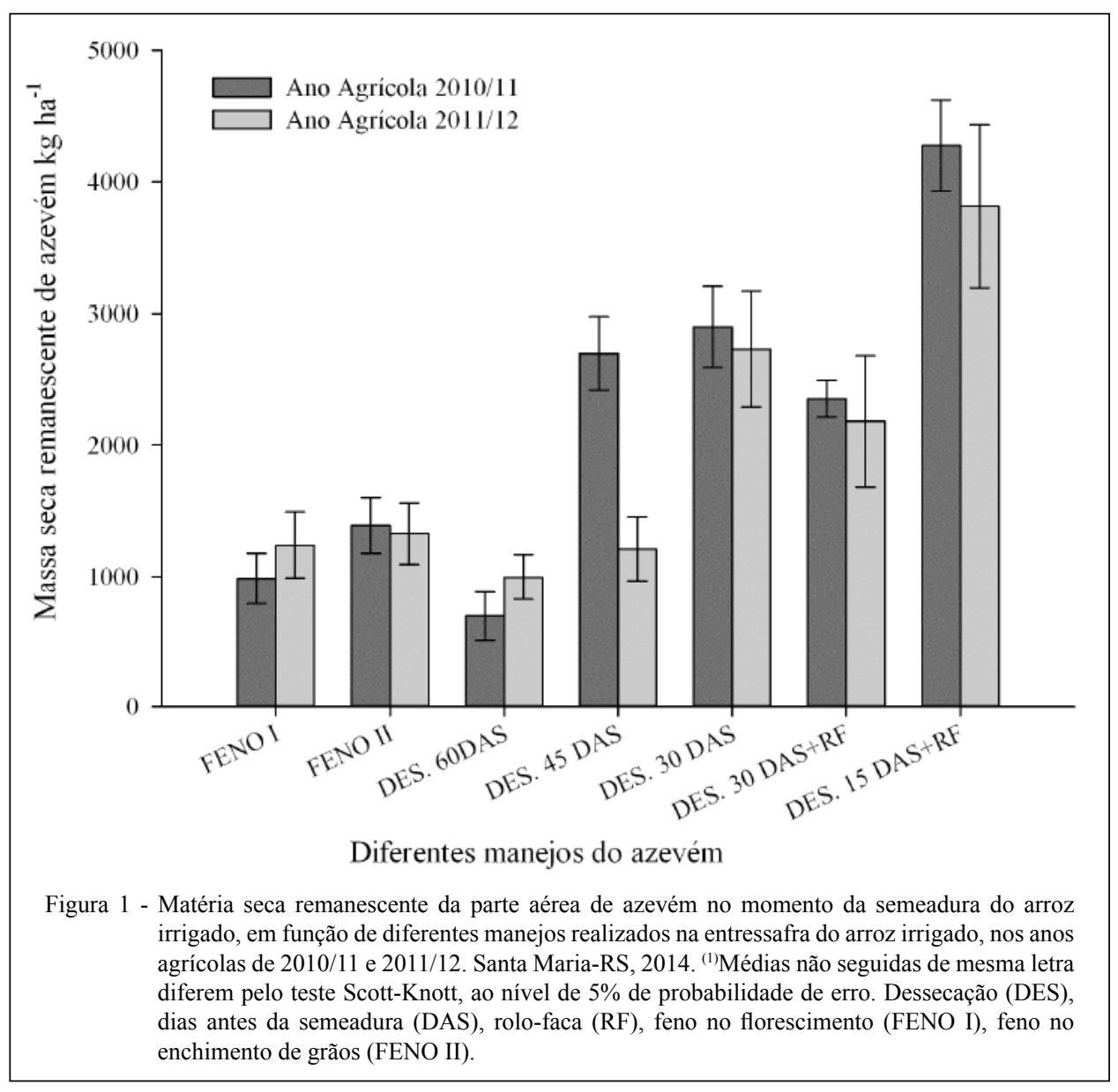

Ciência Rural, v.45, n.12, dez, 2015. 
destacar que a quantidade presente na superfície do solo interfere na perda de água por alterar a ação dos elementos meteorológicos que compõem a demanda evaporativa da atmosfera (CHEN et al., 2007).

$\mathrm{O}$ uso do implemento agrícola rolo-faca proporciona maior contato dos resíduos de azevém com o solo e, assim, acelera o processo de decomposição dos resíduos vegetais, como observado para a dessecação realizada aos $30 \mathrm{DAS}+\mathrm{RF}$, onde reduziu em $20 \%$ a massa seca remanescente, em comparação ao tratamento sem o uso do implemento rolo-faca (30 DAS).

No entanto, os diferentes manejos adotados não retardaram a semeadura do arroz irrigado, que foi realizada na época preferencial para a cultura, na segunda quinzena do mês de outubro, nos dois anos de estudo, ou seja, no momento em que o arroz pode expressar o máximo potencial de rendimento de grãos.

Os teores de N, P e K encontrados na planta de arroz irrigado foram afetados pelos tratamentos utilizados (Tabela 1). A dessecação aos 15 DAS+RF resultou num menor valor de $\mathrm{N}$ na planta de arroz no estádio fenológico $\mathrm{V}_{3}$, para o ano agrícola de 2010/11, evidenciando uma redução de $11 \%$ em relação ao tratamento pousio. Esse comportamento pode ser atribuído à maior relação $\mathrm{C} / \mathrm{N}$ nos resíduos vegetais do azevém em função da maior proporção de colmos nos estádios fenológicos mais adiantados (TEIXEIRA et al., 2011), diminuindo, assim, a velocidade de decomposição dos resíduos vegetais aos 15 DAS+RF, quando comparado aos demais tratamentos.

As plantas de azevém, dessecadas com maior antecedência à semeadura do arroz irrigado, tendem a apresentar uma menor relação $\mathrm{C} / \mathrm{N}$, bem como maior proporção de folhas em relação a colmos de azevém, onde, além de aumentar a velocidade de decomposição dos resíduos vegetais, proporcionam maior contato entre as folhas e o solo, culminando em maior área exposta para ação dos microrganismos do solo. No estádio fenológico $\mathrm{V}_{6}$, não houve diferença para o teor de $\mathrm{N}$ avaliado nas plantas de arroz irrigado.

Para o ano agrícola de 2011/12, o teor de $\mathrm{N}$ nas plantas de arroz avaliado no estádio fenológico $\mathrm{V}_{3}$ apresentou pouca variação entre os diferentes manejos da massa de azevém; os menores teores foram observados para as dessecações realizadas aos 30 e aos 45 DAS, além do tratamento com corte do azevém no florescimento para feno (Feno I). No estádio fenológico $\mathrm{V}_{6}$ das plantas de arroz, o efeito do manejo empregado na massa de azevém foi mais pronunciado; os tratamentos com manejo de dessecação com maior antecedência à semeadura do arroz $(60,45$ e 30 DAS) apresentaram os maiores teores de $\mathrm{N}$ nas plantas. Isso evidencia que a dessecação realizada ao 15 DAS+RF resulta num período menor de aerobiose para os microrganismos do solo realizarem a mineralização do $\mathrm{N}$ dos resíduos vegetais.

Os teores de P na planta de arroz avaliados nos dois estádios fenológicos não foram influenciados pelos diferentes manejos realizados no período de entressafra do arroz irrigado. Isso possivelmente devese à baixa concentração de $\mathrm{P}$ liberado pela cultura do azevém após a realização das dessecações, pois há a tendência de liberação mais lenta desse nutriente dos resíduos vegetais das gramíneas (GIACOMINI et al., 2003). É importante ressaltar que a demanda nutricional de $\mathrm{P}$ pelas plantas de arroz irrigado é inferior em comparação à demanda de N e K (SILVA et al., 2012). Dessa forma, a adubação de base utilizada na semeadura do arroz $\left(60 \mathrm{~kg} \mathrm{P}_{2} \mathrm{O}_{5}\right.$ ha $\left.^{-1}\right)$ pode ter sido suficiente para o nível de produtividade obtido, não sendo influenciado pelos manejos utilizados.

Com relação aos teores de $\mathrm{K}$ na planta de arroz, para ambos os anos agrícolas estudados, os menores teores foram observados nos manejos com dessecações com maior antecedência à semeadura do arroz e no manejo com corte do azevém no florescimento para feno (Feno I), além do pousio. Esse fato pode estar relacionado com a perda do $\mathrm{K}$ liberado pelas plantas de azevém, ou com a incapacidade de a planta de arroz irrigado absorver o nutriente naquele momento. Normalmente, a adição de resíduos vegetais aumenta a disponibilidade do K no solo, pela intensificação da atividade microbiana ou pela liberação direta de nutrientes dos resíduos vegetais e, assim, as plantas são beneficiadas com maior disponibilidade do nutriente (SOUSA \& BORTOLON, 2002).

O estande inicial de plantas de arroz irrigado foi influenciado pelos diferentes manejos realizados na cultura do azevém (Tabela 2), sendo que a dessecação aos 15 DAS+RF apresentou os menores valores nos dois anos agrícolas estudados (2010/11 e 2011/12). Um dos fatores determinantes para esse resultado foi a presença da maior quantidade de massa seca remanescente de azevém sobre a superfície do solo no momento da semeadura do arroz irrigado, acarretando em menor contato da semente com o solo.

É importante ressaltar que o estande inicial de plantas foi superior no manejo com corte do azevém no florescimento para feno (Feno I), quando comparado aos tratamentos com dessecação mais próxima da semeadura do arroz irrigado. Esse aspecto pode indicar que a agregação de renda da propriedade através da produção de feno de azevém em áreas de várzea não influencia negativamente no estabelecimento da cultura do arroz irrigado em sucessão. 
Tabela 1 - Teores médios de nitrogênio $(\mathrm{N})$, fósforo $(\mathrm{P})$ e potássio $(\mathrm{K})$ na matéria seca do arroz irrigado, em dois estádios fenológicos, em função de manejos da palha do azevém no período de entressafra nos anos agrícolas de 2010/11 e 2011/12. Santa Maria-RS, 2014.

\begin{tabular}{|c|c|c|c|c|c|c|}
\hline \multirow[t]{2}{*}{ Tratamentos } & \multicolumn{2}{|c|}{----Teor de $\mathrm{N}\left(\mathrm{g} \mathrm{kg}^{-1}\right)-$} & \multicolumn{2}{|c|}{--------Teor de P $\left(\mathrm{g} \mathrm{kg}^{-1}\right)-------$} & \multicolumn{2}{|c|}{----Teor de $\mathrm{K}\left(\mathrm{g} \mathrm{kg}^{-1}\right)------$} \\
\hline & $\mathrm{V}_{3}{ }^{1}$ & $\mathrm{~V}_{6}$ & $\mathrm{~V}_{3}$ & $\mathrm{~V}_{6}$ & $\mathrm{~V}_{3}$ & $\mathrm{~V}_{6}$ \\
\hline Pousio & $42,6 \mathrm{a}^{2}$ & $28,3^{\text {ns }}$ & $5,9^{\text {ns }}$ & $2,8^{\mathrm{ns}}$ & $35,3 \mathrm{~b}$ & $32,0^{\mathrm{ns}}$ \\
\hline Feno I & $40,5 \mathrm{a}$ & 26,6 & 4,8 & 2,6 & $36,3 \mathrm{~b}$ & 34,0 \\
\hline Feno II & $40,7 \mathrm{a}$ & 28,6 & 5,2 & 2,8 & $38,0 \mathrm{a}$ & 35,0 \\
\hline Des. $60 \mathrm{DAS}^{3}$ & $43,4 \mathrm{a}$ & 30,6 & 5,4 & 3,4 & $36,5 \mathrm{~b}$ & 33,0 \\
\hline Des. 45 DAS & $40,2 \mathrm{a}$ & 27,7 & 5,4 & 3,7 & $35,5 \mathrm{~b}$ & 33,3 \\
\hline Des. 30 DAS & $40,6 \mathrm{a}$ & 28,9 & 5,7 & 2,7 & $39,8 \mathrm{a}$ & 31,3 \\
\hline Des. 30 DAS+RF & $40,2 \mathrm{a}$ & 29,2 & 5,3 & 2,3 & $37,5 \mathrm{a}$ & 34,5 \\
\hline Des. $15 \mathrm{DAS}+\mathrm{RF}^{4}$ & $36,5 \mathrm{~b}$ & 30,0 & 5,5 & 3,3 & $39,3 \mathrm{a}$ & 32,5 \\
\hline Média & 40,5 & 28,7 & 5,4 & 3,0 & 37,6 & 33,2 \\
\hline $\mathrm{CV}(\%)$ & 4,6 & 6,1 & 9,1 & 9,5 & 3,9 & 5,8 \\
\hline Pousio & $36,0 \mathrm{a}$ & $\begin{array}{l}28,0 \mathrm{~b} \\
\text {--Ano agrí }\end{array}$ & $\begin{array}{r}2011 / 1 \\
5,2^{\text {ns }}\end{array}$ & $2,9^{\mathrm{ns}}$ & $37,1 \mathrm{~b}$ & $38,3^{\mathrm{ns}}$ \\
\hline Feno $\mathrm{I}^{5}$ & $34,3 \mathrm{~b}$ & $32,2 \mathrm{a}$ & 5,9 & 3,0 & $35,5 \mathrm{~b}$ & 36,8 \\
\hline Feno $\mathrm{II}^{6}$ & $35,3 \mathrm{a}$ & $26,6 \mathrm{~b}$ & 6,5 & 3,1 & $38,6 \mathrm{a}$ & 38,3 \\
\hline Des. 60 DAS & $35,8 \mathrm{a}$ & $30,2 \mathrm{a}$ & 5,7 & 2,8 & $34,8 \mathrm{~b}$ & 36,0 \\
\hline Des. 45 DAS & $32,9 \mathrm{~b}$ & $31,3 \mathrm{a}$ & 6,1 & 3,6 & $41,4 \mathrm{a}$ & 38,8 \\
\hline Des. 30 DAS & $34,3 \mathrm{~b}$ & $30,4 \mathrm{a}$ & 6,0 & 3,3 & $40,6 \mathrm{a}$ & 39,0 \\
\hline Des. $30 \mathrm{DAS}+\mathrm{RF}$ & $36,4 \mathrm{a}$ & $30,2 \mathrm{a}$ & 7,2 & 4,1 & $40,1 \mathrm{a}$ & 41,0 \\
\hline Des. 15 DAS+RF & $35,8 \mathrm{a}$ & $23,9 \mathrm{c}$ & 6,0 & 3,3 & $40,8 \mathrm{a}$ & 40,0 \\
\hline Média & 35,1 & 29,1 & 6,1 & 3,3 & 38,6 & 38,5 \\
\hline $\mathrm{CV}(\%)$ & 3,4 & 6,9 & 8,6 & 11,7 & 5,7 & 10,5 \\
\hline
\end{tabular}

${ }^{(1)}$ Estádio fenológico segundo a escala proposta por COUNCE et al. (2000); ${ }^{(2)}$ médias não seguidas de mesma letra diferem pelo teste ScottKnott, em nível de $5 \%$ de probabilidade de erro; ${ }^{\text {ns }}$ não significativo pelo teste $\mathrm{F} ;{ }^{(3)}$ dias antes da semeadura do arroz irrigado; ${ }^{(4)}$ rolo-faca; ${ }^{(5)}$ feno no florescimento; ${ }^{(6)}$ feno no enchimento de grãos.

O número de colmos por planta de arroz foi influenciado pelos diferentes manejos do azevém no período de entressafra, verificando maior número de colmos naqueles tratamentos em que a população de plantas foi menor, como ocorreu na dessecação aos 15 DAS+RF, onde o número de colmos por plantas foi superior desde o estádio fenológico $\mathrm{V}_{4}$ até $\mathrm{V}_{9}$ para ambos os anos agrícolas estudados. Isso pode estar relacionado à compensação pelo baixo estande inicial de plantas, já que uma maior quantidade de área disponível no dossel vegetativo estimula o perfilhamento da planta de arroz (PRABHA et al., 2011).

Nos dois anos de estudo, o acúmulo de massa seca da parte aérea do arroz foi influenciado pelos diferentes manejos realizados no azevém, sendo que o manejo com dessecação aos $15 \mathrm{DAS}+\mathrm{RF}$ foi o que apresentou os menores acúmulos nos estádios fenológicos avaliados. Essa resposta pode estar relacionada ao estiolamento verificado nas plantas de arroz em função da elevada quantidade de massa seca remanescente de azevém, o qual foi de aproximadamente 4 toneladas ha $^{-1}$ (Figura 1). Esse fato pode ter alterado a luminosidade para as plantas de arroz, pois MEROTTO JR et al. (2002), avaliando a variação da qualidade da luz através da presença de plantas daninhas ou da reflexão da luz resultante da presença de seis toneladas de palha de aveia sobre o solo, encontraram que a cobertura do solo com palha influencia diretamente a altura das plantas de soja em função das formas de luminosidade utilizada. Além disso, no sistema de plantio direto, a presença de elevadas quantidades de resíduos vegetais sobre o solo pode resultar na produção de ácidos orgânicos de baixo peso molecular e cadeia curta, como os ácidos propiônico e butírico (SCHMIDT et al., 2007).

O rendimento de grãos do arroz irrigado no ano agrícola de 2010/11 não foi afetado pelos diferentes manejos realizados na cultura do azevém. Resultados semelhantes foram obtidos por CORREIA et al. (2013), os quais não verificaram diferença no rendimento de grãos do arroz para os diferentes 
Tabela 2 - Estande inicial de plantas (EP), número de colmos planta ${ }^{-1}$, acúmulo de matéria seca (AMS) e rendimento de grãos (RG) de arroz irrigado em função de manejos da palha do azevém no período de entressafra nos anos agrícolas de 2010/11 e 2011/12. Santa Maria-RS, 2014.

\begin{tabular}{|c|c|c|c|c|c|c|c|c|}
\hline \multirow{3}{*}{ Tratamentos } & \multirow{3}{*}{$\mathrm{EP}\left(\mathrm{pl} . \mathrm{m}^{-2}\right)$} & \multicolumn{4}{|c|}{ Colmos planta ${ }^{-1}$} & \multirow{2}{*}{\multicolumn{2}{|c|}{$\begin{array}{l}-1 \\
-\end{array}$}} & \multirow{3}{*}{$\mathrm{RG}\left(\mathrm{kg} \mathrm{ha}^{-1}\right)$} \\
\hline & & \multicolumn{4}{|c|}{ 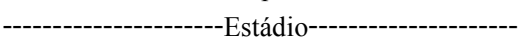 } & & & \\
\hline & & $\mathrm{V}_{4}$ & $\mathrm{~V}_{5}$ & $\mathrm{~V}_{7}$ & $\mathrm{~V}_{9}$ & $\mathrm{~V}_{3}$ & $\mathrm{~V}_{6}$ & \\
\hline Pousio & $250 \mathrm{~b}$ & $2,0 \mathrm{a}$ & $3,5 \mathrm{a}$ & $4,3 \mathrm{a}$ & $4,2 \mathrm{a}$ & $81 \mathrm{~b}^{2}$ & $2266 \mathrm{a}$ & $12774^{\mathrm{ns}}$ \\
\hline Feno I & $297 \mathrm{a}$ & $1,4 \mathrm{~b}$ & $2,5 \mathrm{~b}$ & $3,0 \mathrm{~b}$ & $3,2 \mathrm{~b}$ & $133 \mathrm{a}$ & 1965 a & 12650 \\
\hline Feno II & $242 b$ & $1,9 \mathrm{a}$ & $3,9 \mathrm{a}$ & $4,4 \mathrm{a}$ & $4,4 \mathrm{a}$ & $121 \mathrm{a}$ & $1558 \mathrm{~b}$ & 12544 \\
\hline Des. $60 \mathrm{DAS}^{3}$ & $269 \mathrm{~b}$ & $1,3 \mathrm{~b}$ & $2,5 \mathrm{~b}$ & $3,5 \mathrm{~b}$ & $3,3 \mathrm{~b}$ & $89 \mathrm{~b}$ & $1480 \mathrm{~b}$ & 12290 \\
\hline Des. 45 DAS & $278 \mathrm{a}$ & $1,6 \mathrm{~b}$ & $2,6 \mathrm{~b}$ & $3,3 \mathrm{~b}$ & $3,3 \mathrm{~b}$ & $113 \mathrm{a}$ & $1703 \mathrm{a}$ & 11951 \\
\hline Des. 30 DAS & $296 \mathrm{a}$ & $1,4 \mathrm{~b}$ & $2,5 \mathrm{~b}$ & $3,2 \mathrm{~b}$ & $3,5 \mathrm{~b}$ & $94 \mathrm{~b}$ & $2131 \mathrm{a}$ & 12244 \\
\hline Des. 30 DAS+RF & $289 \mathrm{a}$ & $1,5 \mathrm{~b}$ & $3,0 \mathrm{~b}$ & $3,4 \mathrm{~b}$ & $3,5 \mathrm{~b}$ & $81 \mathrm{~b}$ & $2119 a$ & 12470 \\
\hline Des. $15 \mathrm{DAS}+\mathrm{RF}^{4}$ & $184 \mathrm{c}$ & $1,8 \mathrm{a}$ & $3,4 \mathrm{a}$ & $4,8 \mathrm{a}$ & $5,0 \mathrm{a}$ & $49 \mathrm{c}$ & $1345 \mathrm{~b}$ & 12091 \\
\hline Média & 262 & 1,6 & 3,0 & 3,7 & 3,8 & 95 & 1821 & 12377 \\
\hline CV $(\%)$ & 9,09 & 7,43 & 9,03 & 9,38 & 9,29 & 9,59 & 8,61 & 5,59 \\
\hline Pousio & $240 \mathrm{a}$ & $2,4 b$ & $\begin{array}{l}\text { Ano ag } 1 \\
3,3 \mathrm{c}\end{array}$ & $\begin{array}{c}\text { de } 201 \\
4,2 \mathrm{c}\end{array}$ & $3,9 \mathrm{c}$ & $69 \mathrm{a}$ & $1627 \mathrm{a}$ & $11269 \mathrm{~b}$ \\
\hline Feno I ${ }^{5}$ & $226 \mathrm{a}$ & $2,4 \mathrm{~b}$ & $3,1 \mathrm{c}$ & $4,7 \mathrm{c}$ & $4,8 \mathrm{~b}$ & $63 \mathrm{a}$ & $1316 \mathrm{~b}$ & $11438 \mathrm{~b}$ \\
\hline Feno $\mathrm{II}^{6}$ & $193 \mathrm{~b}$ & $2,5 \mathrm{~b}$ & $3,5 \mathrm{c}$ & $5,2 \mathrm{~b}$ & $5,7 \mathrm{~b}$ & $63 \mathrm{a}$ & $963 \mathrm{c}$ & $10024 \mathrm{c}$ \\
\hline Des. 60 DAS & $235 \mathrm{a}$ & $2,0 \mathrm{~b}$ & $3,2 \mathrm{c}$ & $4,3 \mathrm{c}$ & $4,7 \mathrm{~b}$ & $78 \mathrm{a}$ & $1585 \mathrm{a}$ & $12296 \mathrm{a}$ \\
\hline Des. 45 DAS & $212 b$ & $2,3 \mathrm{~b}$ & $3,5 \mathrm{c}$ & $4,2 \mathrm{c}$ & $4,8 \mathrm{~b}$ & $64 \mathrm{a}$ & $1117 \mathrm{~b}$ & $10765 \mathrm{~b}$ \\
\hline Des. 30 DAS & $202 \mathrm{~b}$ & $1,5 \mathrm{c}$ & $3,9 \mathrm{~b}$ & $4,5 \mathrm{c}$ & $4,5 \mathrm{~b}$ & $67 \mathrm{a}$ & $868 \mathrm{c}$ & $10220 \mathrm{c}$ \\
\hline Des. 30 DAS+RF & $151 \mathrm{c}$ & $2,9 \mathrm{a}$ & $4,2 \mathrm{~b}$ & $5,3 \mathrm{~b}$ & $5,6 \mathrm{~b}$ & $57 \mathrm{a}$ & $731 \mathrm{~d}$ & $10251 \mathrm{c}$ \\
\hline Des. 15 DAS+RF & $99 \mathrm{~d}$ & $2,4 \mathrm{~b}$ & $4,8 \mathrm{a}$ & $5,9 \mathrm{a}$ & $6,2 \mathrm{a}$ & $34 \mathrm{~b}$ & $610 \mathrm{~d}$ & $8590 \mathrm{~d}$ \\
\hline Média & 195 & 2,3 & 3,7 & 5,0 & 5,2 & 62 & 1102 & 10657 \\
\hline CV (\%) & 6,8 & 9,49 & 8,89 & 7,74 & 7,55 & 9,78 & 8,55 & 6,79 \\
\hline
\end{tabular}

${ }^{(1)}$ Estádio fenológico segundo a escala proposta por COUNCE et al. (2000); ${ }^{(2)}$ médias não seguidas de mesma letra diferem pelo teste ScottKnott, em nível de $5 \%$ de probabilidade de erro; ${ }^{\text {ns }}$ não significativo pelo teste $\mathrm{F} ;{ }^{(3)}$ dias antes da semeadura do arroz irrigado; ${ }^{(4)}$ rolo-faca; ${ }^{(5)}$ feno no florescimento; ${ }^{(6)}$ feno no enchimento de grãos.

manejos empregados na cultura do azevém, no período de entressafra e pousio.

Para o ano agrícola 2011/12, a dessecação realizada aos 60 DAS resultou no maior rendimento de grãos de arroz (12296kg ha' ${ }^{-1}$, no entanto, a dessecação do azevém aos 15 DAS+RF apresentou uma redução de $30 \%$ no rendimento de grãos, em comparação à dessecação 60 DAS. Esse fato pode estar associado ao menor estande inicial de plantas, e também ao baixo teor de $\mathrm{N}$ verificado no estádio fenológico $V_{6}$, visto que esse nutriente é determinante na emissão de panículas e no enchimento de grãos em gramíneas (ZHANG et al., 2008).

\section{CONCLUSÃO}

Há redução do estande inicial de plantas de arroz irrigado à medida que a dessecação do azevém se aproxima da semeadura do arroz.

A utilização do azevém em áreas de várzea intensifica a ciclagem de nutrientes, mas recomenda-se que, em azevém não pastejado, a dessecação seja realizada com antecedência de 60 dias da semeadura do arroz irrigado para não prejudicar o rendimento de grãos de arroz.

A produção de feno de azevém pode ser uma alternativa viável economicamente para entressafra em áreas de várzea, pois não prejudica o estabelecimento inicial de plantas de arroz irrigado.

\section{AGRADECIMENTOS}

Ao Conselho Nacional de Desenvolvimento Científico e Tecnológico $(\mathrm{CNPq})$ e à Coordenação de Aperfeiçoamento de Pessoal de Nível Superior (CAPES) pelo suporte financeiro e pelas bolsas de estudo e pesquisa e ao segundo autor pela bolsa de produtividade em pesquisa.

\section{REFERÊNCIAS}

CHEN, S.Y. et al. Effects of straw mulching on soil temperature, evaporation and yield of winter wheat: field experiments on 
the North China Plain. Annals of Applied Biology, v.150, n.3, p.261-268, 2007. Disponível em: <http://dx.doi.org/10.11 11/j.1744-7348.2007.00144.x>. Acesso em: 7 ago. 2013. doi: $10.1111 / \mathrm{j} .1744-7348.2007 .00144 . \mathrm{x}$

COUNCE, P.A. et al. A uniform, objective, and adaptive system for expressing rice development. Crop Science, v.40, n.2, p.436-443, 2000. Disponível em: <http://dx.doi.org/10.2135/cropsci2000.402436x>. Acesso em: 7 ago. 2013. doi: 10.2135/cropsci2000.402436x.

CORREIA, S.L. et al. Estratégias de manejo da palha de azevém para cultivo do arroz irrigado em sucessão. Revista Brasileira de Ciência do Solo, v.37, n.2, p.512-520, 2013. Disponível em: $<$ http://dx.doi.org/10.1590/S0100-06832013000200022>. Acesso em: 10 out. 2013. doi: 10.1590/S0100-06832013000200022.

CRUSCIOL, C.A.C. et al. Taxas de decomposição e de liberação de macronutrientes da palha de aveia preta em plantio direto. Bragantia, v.67, n.2, p.481-489, 2008. Disponível em: <http:// dx.doi.org/10.1590/S0006-87052008000200024>. Acesso em: 10 ago. 2013. doi: 10.1590/S0006-87052008000200024.

EMBRAPA. Centro Nacional de Pesquisa de Solos. Sistema brasileiro de classificação dos solos. Brasília: Embrapa-SPI, 2006. 306p.

GIACOMINI, S.J. et al. Liberação de fósforo e potássio durante a decomposição de resíduos culturais em plantio direto. Pesquisa Agropecuária Brasileira, v.38, n.9, p.1097-1104, 2003. Disponível em: <http://dx.doi.org/10.590/S0100-204X2003000900011>. Acesso em: 7 ago. 2013. doi: 10.590/S0100-204X2003000900011.

MENEZES, V.G. et al. Semeadura direta de genótipos de arroz irrigado em sucessão a espécies de cobertura de solo no inverno. Pesquisa Agropecuária Brasileira, v.36, n.9, p.11071115, 2001. Disponível em: <http://dx.doi.org/10.1590/S0100204X2001000900004>. Acesso em: 7 ago. 2013. doi: 10.1590/ S0100-204X2001000900004.

MEROTTO JR, A. et al. Interferência das plantas daninhas sobre o desenvolvimento inicial de plantas de soja e arroz através da qualidade da luz. Planta Daninha, v.20, v.20, n.1, p.9-16, 2002. Disponível em: <http://dx.doi.org/10.1590/S010083582002000100002>. Acesso em: 9 ago. 2013. doi: 10.1590/ S0100-83582002000100002.

PRABHA, A.C.S. et al. System of rice intensification principles on growth parameters, yield attributes and yields of rice (Oryza sativa L.). Journal of Agronomy, v.10, n.1, p.27-33, 2011. Disponível em: <http://dx.doi.org/0.3923/ja.2011.27.33>. Acesso em: 7 ago. 2013. doi: $10.3923 /$ ja.2011.27.33.
REDDY, K.N. Effects of cereal and legume cover crop residues on weeds, yield, and net return in soybean (Glycine max). Weed Technology, v.15, p.660-668, 2001. Disponível em: $<$ http://dx.doi. org/10.1614/0890-037X(2001)015[0660:EOCALC]2.0.CO;2> Acesso em: 7 ago. 2013. doi: 10.1614/0890-037X(2001)015[066 $0:$ EOCALC]2.0.CO;2.

SCHMIDT, F. et al. Toxidez pelos ácidos propiônico e butírico em plântulas de arroz. Ciência Rural, v.37, n.3, p.720-726, 2007. Disponível em: <http://dx.doi.org/10.1590/S010384782007000300018>. Acesso em: 7 ago. 2013. doi: 10.1590/ S0103-84782007000300018.

SILVA, L.S. et al. Teores de macronutrientes em cultivares de arroz irrigado de acordo com a parte da planta analisada e do estádio de desenvolvimento. Revista Ceres, v.59, n.4, p.544549, 2012. Disponível em: <http://dx.doi.org/10.1590/S0034737X2012000400016>. Acesso em: 10 ago. 2013. doi: 10.1590/ S0034-737X2012000400016.

SOSBAI - SOCIEDADE SUL-BRASILEIRA DE ARROZ IRRIGADO. Arroz irrigado: recomendações técnicas da pesquisa para o Sul do Brasil, 28. Reunião Técnica da Cultura do Arroz Irrigado. Bento Gonçalves, RS - Porto Alegre: SOSBAI, 2010. 188p.

SOUSA, R.O.; BORTOLON, L. Crescimento radicular e da parte aérea do arroz (Oryza sativa L.) e absorção de nutrientes em solução nutritiva com diferentes concentrações de ácido acético. Revista Brasileira de Agrociência, v.8, n.3, p.231-235, 2002.

TEDESCO, M.J. et al. Análises de solo, plantas e outros materiais 2. ed. Porto Alegre: Departamento de Solos. Universidade Federal do Rio Grande do Sul, 1995. 174p. (Boletim técnico, n.5).

TEIXEIRA, M. et al. Decomposição e liberação de nutrientes da parte aérea de plantas de milheto e sorgo. Revista Brasileira Ciência do Solo, v.35, n.3, p.867-876, 2011. Disponível em: $<$ http://dx.doi.org/10.1590/S0100-06832011000300021>. Acesso em: 7 ago. 2013. doi: 10.1590/S0100-06832011000300021.

VEZZANI, F.M.; MIELNICZUK, J. Uma visão sobre qualidade do solo. Revista Brasileira de Ciência do Solo, v.33, n.4, p.743755, 2009. Disponível em: <http://dx.doi.org/10.1590/S010006832009000400001>. Acesso em: 10 ago. 2013. doi: 10.1590/ S0100-06832009000400001.

ZHANG, Y. et al. Effects of nitrogen nutrition on grain yield of upland and paddy rice under different cultivation methods. Acta Agronomica Sinica, v.38 n.6, p.1005-1013, 2008. Disponível em: $<$ http://dx.doi.org/10.1016/S1875-2780(08)60038-3>. Acesso em: 7 ago. 2013. doi: 10.1016/S1875-2780(08)60038-3. 